\title{
The Impact of Ownership Structure on the Private Information: An Empirical Study Based on China's A-Share Market
}

\author{
Zhisen Zeng ${ }^{1}$, \& Yuying $\mathrm{Li}^{1}$ \\ ${ }^{1}$ International Business School, Jinan University, China \\ Correspondence: Zhisen Zeng, Finance Department of International Business School, Jinan University, Qianshan \\ Road 206\#, Zhuhai City, Guangdong Province, Post NO. 519070, China.
}

Received: May 19, 2021

doi:10.5539/ibr.v14n7p12
Accepted: June 11, $2021 \quad$ Online Published: June 16, 2021

URL: https://doi.org/10.5539/ibr.v14n7p12

\begin{abstract}
Ownership structure will have a certain impact on the private information of a company, which will have a complex impact on the financial market. Therefore, it is necessary to study the impact of the ownership structure on private information. This paper uses the monthly data of individual stocks in A-share from 2019 to 2020 to calculate the goodness of fit $R^{2}$ of the CAPM model to measure the private information content, and then conducts multiple analysis processes such as multicollinearity analysis and heteroscedasticity analysis to ensure the accuracy of the model. Then, this paper uses the WLS regression method for final calculation. The results show that the higher ownership concentration, the less private information content, the weaker private information arbitrage. Finally, this paper puts forward some valuable suggestions for China's financial market based on the empirical results.
\end{abstract}

Keywords: ownership structure, private information, CAPM model, WLS regression

\section{Introduction}

The content of various types of information in the financial market can reflect the efficiency of a market to a certain extent, and it is also an important basis for measuring whether the financial market is running well. Compared with the developed countries, China's financial market opened relatively late and its openness is relatively weak. Therefore, the private information content in China's stock prices may be higher, and the phenomenon of private information arbitrage may become more serious. Excessive private information content will lead to increased information asymmetry, damage the interests of shareholders, deepen the unfairness and opacity of the stock market, and is not conducive to the healthy development of the stock market. Therefore, it is necessary to analyze the factors affecting private information content. At the same time, existing research shows that ownership structure has an important impact on private information. This paper will apply a method to measure the impact of ownership structure on private information and take the A-share market as the research object for empirical research, verify the hypothesis, and put forward relevant suggestions, finally provide reference for the development of China 's financial market.

The main structure of this paper is as follows. Firstly, this paper reviews the relevant literature and theories, and then proposes hypotheses. Secondly, it uses the method proposed by Roll (1988) to measure the private information content in stock prices and constructs a regression model for empirical analysis. Finally, it verifies the hypotheses and draws relevant conclusions.

\section{Literature Review}

As early as the last century, Roll (1988) proposed that $R^{2}$ can be used to measure the content of private information in stock prices. Subsequently, many scholars conducted in-depth studies on private information based on this method. Feng Yongfu, Dong Yan, and Yuan Zebo (2009) conducted an empirical analysis on China based on Roll's study and found that the higher the shareholding ratio of institutional investors, the higher the degree of investors use private information for arbitrage, and the higher the shareholding ratio of the largest shareholder, the higher the degree of private information arbitrage; Xu Feng, Fan Daqiang, and Xie Dan (2012) used the generalized difference method to test the hidden transaction hypothesis that private information does have a substantial impact on the price fluctuations in stock market. Moreover, the owners of private information operate through a certain type of transaction, which effectively prevents the excessive leakage of private 
information and ensures the use of private information to profit; Kong Xiangfeng, Zhao Yujie, and Ma Yue (2015) have similar research ideas with this paper, and it proves that there is a positive relationship between the proportion of the largest shareholder's shareholding and private information arbitrage, so this study can be used as a supplementary study of this paper.

Regarding the relationship between public information and private information, Wang Yan (2006) used non-parametric method to prove that information disclosure does not necessarily reduce the degree of information asymmetry, that is, the two may have a complementary relationship; Wang Chunfeng, Zhang Shuqi, and Fang Zhenming ( 2018 ) used VPIN as the proxy variable of private information to further verify that there may be a complementary effect of public information and private information in China's A-share market; Liu Jiong ( 2019 ) studied the speed of information integration, and used multiple regression to verify the competitive relationship between public information and private information integration, and verify that more private information integration reduces the speed of information integration of public information.

In summary, many scholars have conducted a lot of research on the relationship between information and the stock market, and different research objects and methods are likely to lead to completely different conclusions. At the same time, domestic research on the impact of ownership structure on private information is not much, so this paper can fill this gap to a certain extent. Moreover, focusing on China's A-share market for research has better applicability to the actual situation in China, whose conclusions will have great reference value, and the suggestions put forward for the conclusion will also have great practical significance.

\section{Existing Related Theories and Hypotheses}

\subsection{Characteristics of China's Ownership Structure}

Since China is a socialist country, the proportion of state-owned capital in listed enterprises will be greater than that in capitalist countries, and special products such as tradable shares and non-tradable shares have been born. However, with the continuous changes of China's development strategy, and with the continuous deepening of equity reform, the proportion of state-owned capital holdings is gradually decreasing, and the phenomenon of the ' dominance ' of state-owned shares is also weakening. Wang Xinhong and Zhang Zhuanjun (2019) also confirmed this by data analysis. They also pointed out that the ownership concentration of listed enterprises in China is still high, and the ownership concentration of the main board listed enterprises is higher than that of the SME board and GEM.

Therefore, the ownership structure of listed enterprises in China has the typical characteristics of large proportion of state-owned holding and high ownership concentration.

\subsection{Efficient Market Hypothesis Theory}

In order to better understand the impact of ownership structure on the private information, it is necessary to explain the efficient market hypothesis. Malkiel and Fama(1970) proposed that effective markets can be divided into three categories, namely weak efficient market, semi-strong efficient market and strong efficient market. Weak efficient market refers to prices that have reflected all historical information, technical analysis methods are invalid, and public or private information is needed to obtain excess returns; semi-strong efficient market refers to prices that have reflected all historical and public information, technical analysis and fundamental analysis methods are ineffective, and private information is needed to obtain excess returns; a strong efficient market refers to that prices have already reflected all information including historical information, public information, and private information, so it is almost impossible to obtain excess returns, but only the average return of the market can be obtained.

The theoretical basis of efficient market hypothesis plays an important role in understanding the relationship between public information and private information, and the impact of ownership structure on private information.

\subsection{The Relationship between Public Information and Private Information}

Many scholars believe that public information and private information have substitution effects and complementary effects. Substitution effect refers to the fact that public information and private information can replace each other. Information disclosure requirements enable private information to be converted into public information after it is published, thereby reducing information asymmetry. Complementary effect means that the increase of public information will lead to the increase of private information, because public information may become the source of private information and become the driving force for some people to collect private information, thereby exacerbating the degree of information asymmetry. Therefore, by understanding the relationship between public information and private information, combined with the efficient market hypothesis, 
we can further explore the impact of information on the market, and we can better study the impact of ownership structure on private information.

\subsection{The Impact of Ownership Concentration on Private Information Arbitrage}

Regarding the impact of ownership concentration on private information, it is mainly the impact of ownership concentration on private information arbitrage, that is, the impact on the degree of investor protection. There are mainly two mainstream views, one is the supervision hypothesis, and the other is the predation hypothesis. The supervision hypothesis refers to that with the increasing of the degree of ownership concentration, there will be gradual convergence between the interests of major shareholders and the interests of the company, so that the major shareholders will strive to maximize the company's profits, and then the interests of small shareholders can also be maximized; the predatory hypothesis is quite the contrary, it means that with the increasing ownership concentration, the degree of information asymmetry between large shareholders and small shareholders will deepen, and large shareholders will be able to grasp more information, which will lead to more private information arbitrage and further damage the interests of other shareholders.

Due to these two different statements, it is difficult to determine the impact of ownership concentration on private information. Therefore, it is necessary to conduct empirical analysis on the A-share market to verify the application of different hypotheses in China, and to better propose targeted suggestions to improve the development of the financial system.

Therefore, this paper proposes the following two hypotheses:

1. In the A-share market, the higher the ownership concentration, the higher the content of private information, that is, the predatory hypothesis is more applicable;

2. In the A-share market, the higher the ownership concentration, the lower the content of private information, that is, the supervisory hypothesis is more applicable.

\section{Empirical Verification}

\subsection{Sample Selection and Data Processing}

This paper selects the available data of all listed enterprises in A-share market, during the two years from 2019 to 2020 , including the Sci-tech Innovation Board and GEM. A total of 4166 samples were initially included, leaving 1429 valid samples after deleting missing and faulty samples. All data in this paper come from Guotaian database.

\subsection{Variable Definition}

(1) Explained Variable

The explained variable selected in this paper is INFO, which can reflect the content of private information to a certain extent. The statistical significance of $R^{2}$ is the ratio of the sum of squares of regression to the sum of squares of total regression in the linear regression model, representing the explanatory power of the linear regression model. The greater the $R^{2}$, the greater the explanatory power of the model. According to Roll (1988), if we want to use $R^{2}$ to measure private information content, we also need to introduce CAPM model, because the $R^{2}$ in CAPM model is actually the explanatory power of systemic factors on individual stocks, rather than the part explained by the model, it can be understood as the impact of noise and private information on individual stocks. The specific calculation formula is as follows:

$$
r_{i}=\alpha+\beta r_{m}+\varepsilon
$$

Among which: $r_{i}$ is the monthly rate of return on individual stocks; $r_{m}$ is the monthly market rate of return, calculated by comprehensive monthly market rate of return that does not consider cash dividend reinvestment and is calculated by weighted average method of total market value; $\alpha$ and $\varepsilon$ are intercepts and random errors, respectively. The regression results of $R^{2}$ are obtained from the data from January 2019 to December 2020.

Since the value of $\left(1-R^{2}\right)$ ranges from 0 to 1 , accurate results cannot be obtained by using least squares regression, so it is necessary to learn from the method of Qi Songchao (2012) and use the following formula to calculate:

$$
I N F O=\log \left(\frac{1-R^{2}}{R^{2}}\right)
$$

In the formula, the higher the content of private information, the larger the INFO. 


\section{(2) Explanatory Variable}

The explanatory variable of this paper is the shareholding ratio SHARE of the largest shareholder that can be used to reflect ownership concentration. The time cut-off point of the data is the shareholding ratio announced on December 31, 2020.

\section{(3) Control Variable}

Since the financial indicators of an enterprise can well reflect its operating conditions, this paper mainly uses the representative financial indicators of the enterprise as the control variable, and takes December 31, 2020 as the time cut-off point. Three mainly financial indicators are as follows:

(1) Debt-to-asset ratio $D A R$. The debt-to-asset ratio can measure the degree of financial risk of an enterprise, and can reflect whether an enterprise is in good operating conditions, so it obviously has an impact on the content of private information.

(2) Total asset turnover rate TAT. The total asset turnover rate can reflect the operating capability of an enterprise. Generally speaking, the higher the total asset turnover rate, the stronger the enterprise's operating capability, and it will also have a greater impact on the content of private information.

(3) Net profit margin on sales NPMS. Net profit margin on sales can reflect the profitability and business prospects of an enterprise, and have an impact on private information. The higher the net profit margin on sales, the stronger the profitability of an enterprise.

\subsection{Model Design}

In order to prove the hypotheses proposed in this paper, a series of regression analysis needs to be performed using the above variables. The specific model is as follows:

$$
I N F O=\alpha+\beta_{1} S H A R E+\beta_{2} D A R+\beta_{3} T A T+\beta_{4} N P M S+\mu
$$

Among which, $\mu$ is the stochastic perturbation term, and $\beta_{1}$ is the most critical coefficient. If the coefficient $\beta_{1}$ is significantly positive, it means that the higher the ownership concentration, the higher the content of private information, that is, the predatory hypothesis is more applicable, and the hypothesis 1 holds, conversely, the hypothesis 2 holds.

\subsection{Empirical Results and Analysis}

\subsubsection{Descriptive Statistics of Variables}

Table 1. Descriptive statistics of variables

\begin{tabular}{cccccc}
\hline & INFO & DAR & NPMS & TAT & SHARE \\
\cline { 2 - 6 } Average Value & 1.297202 & 0.4303722 & -0.108616 & 0.5919944 & 0.3040985 \\
Standard Deviation & 1.575995 & 0.2109005 & 3.376547 & 0.4464785 & 0.1398059 \\
Minimum Value & -4.080332 & 0.0142676 & -95.71913 & 0.0001436 & 0.03 \\
Maximum Value & 13.8998 & 2.175867 & 18.45258 & 5.988063 & 0.8341 \\
\hline
\end{tabular}

Table 1 shows the results of descriptive statistics of variables. It shows that the standard deviation of INFO is large, and the difference between the maximum value and the minimum value is large. Therefore, it can be considered that the private information content of different enterprises in the A-share market is quite different; the maximum and minimum values of $D A R$ are quite different, but its average value is about 0.43 , indicating that the overall debt level of A-share enterprises is relatively normal, and the risk of the A-share market is relatively small; the average value of NPMS is negative, and it has a large standard deviation and extreme deviation. To a certain extent, this shows that the profitability of different A-share enterprises has a large gap, and it does not rule out that individual enterprises have great investment risks; the extreme deviation of SHARE is also relatively large, indicating that there are also great differences in ownership concentration among different enterprises, but its average value reached 0.34 , indicating that most of the listed companies in China have a high ownership concentration. 


\subsubsection{Correlation Analysis}

Table 2. Pearson correlation coefficient matrix

\begin{tabular}{cccccc}
\hline & INFO & SHARE & DAR & NPMS & TAT \\
\hline INFO & 1.000 & & & & \\
SHARE & $-0.051^{*}$ & 1.000 & & & \\
DAR & -0.011 & 0.005 & 1.000 & & \\
NPMS & -0.027 & $0.068^{* * *}$ & $-0.127^{* * *}$ & 1.000 & \\
TAT & -0.029 & 0.042 & $0.116^{* * *}$ & $0.056^{* * *}$ & 1.000 \\
\hline
\end{tabular}

Note. $* * *, * * *$ are significant at the level of $1 \%, 5 \%$ and $10 \%$ respectively.

Table 2 shows the Pearson correlation coefficient between the main variables in this paper. It can be seen that the correlation coefficient between SHARE and INFO is negative, and it is significant at $10 \%$ significance level, indicating that it is likely that ownership concentration and private information content show a negative relationship. That is, the hypothesis 2 proposed above may be established, but further empirical studies are needed to verify it. At the same time, although there is more or less correlation between other variables, it is not very high. That is, there is no serious multicollinearity problem.

\subsubsection{Multicollinearity Analysis}

In order to avoid the problem of multicollinearity in regression, it is first necessary to judge whether the data has multicollinearity. If there is no multicollinearity, the regression conditions of least squares method should be satisfied. The Pearson correlation coefficient matrix above has explained to a certain extent that there is no serious multicollinearity between variables. For the accuracy of the conclusion, this paper uses the method of calculating the variance inflation factor (VIF) to judge the multicollinearity. The calculation results are shown in the following table:

Table 3. VIF calculation results

\begin{tabular}{cccccc}
\hline & DAR & NPMS & TAT & SHARE & Average Value \\
\hline VIF & 1.03 & 1.03 & 1.02 & 1.01 & 1.02 \\
\hline
\end{tabular}

It can be seen that the VIF values in Table 3 are all far less than 10, so it can be considered that there is no multicollinearity in the data and the data meets the requirements of least squares regression.

\subsubsection{Heteroscedasticity Analysis}

To ensure the accuracy of the regression results, it is also necessary to determine whether the data has heteroscedasticity. If there is heteroscedasticity, the least squares regression needs to be corrected; if there is no heteroscedasticity, the regression result is relatively reliable. This paper uses the BP test method to test heteroscedasticity, and the results show that the $\mathrm{p}$ value is 0.0285 , indicating that the null hypothesis is rejected at the 5\% significance level, that is, heteroscedasticity exists and the least squares regression needs to be corrected.

\subsubsection{Regression Analysis}

The results of the BP test have shown that the data has heteroscedasticity, so this paper uses the weighted least squares method (WLS) to correct it. After repeated attempts, this paper finally selects the following formula as the weight $w$ of the weighted least squares method:

$$
w=1 / \sqrt{\exp \left(c_{1} D A R+c_{2} T A T+c_{3} N P M S+c_{4} S H A R E+c_{5} D A R^{2}+c_{6} T A T^{2}+c_{7} N P M S^{2}+c_{8} S H A R E^{2}\right)}
$$

In which, $c_{i}(i=1,2, \cdots, 8)$ is the regression coefficient of each variable in the formula, and the values of each coefficient in the formula are shown in the following table: 
Table 4. Value reference of the coefficients

\begin{tabular}{ccccccccc}
\hline Coefficient & $\mathrm{c}_{1}$ & $c_{2}$ & $c_{3}$ & $c_{4}$ & $c_{5}$ & $c_{6}$ & $c_{7}$ & $c_{8}$ \\
\hline Value & -0.635 & -0.132 & -0.097 & -3.343 & 0.614 & -0.011 & -0.002 & 3.561 \\
\hline
\end{tabular}

The resulting new model is as follows:

$$
w I N F O=w \alpha+w \beta S H A R E+w \beta D A R+w \beta N P M S+w \mu
$$

The results of the regression are shown in the following table:

Table 5. WLS regression results

\begin{tabular}{|c|c|c|c|c|c|c|}
\hline INFO & Coef. & Std. Err. & $\mathrm{t}$ & $\mathrm{P}>\mathrm{t}$ & \multicolumn{2}{|c|}{ [95\% Conf. Interval] } \\
\hline SHARE & -0.373 & 0.201 & -1.85 & 0.064 & -0.768 & 0.022 \\
\hline$D A R$ & 0.21 & 0.139 & 1.51 & 0.131 & -0.062 & 0.482 \\
\hline NPMS & -0.013 & 0.002 & -8.07 & 0.000 & -0.017 & -0.010 \\
\hline$T A T$ & -0.073 & 0.039 & -1.86 & 0.064 & -0.15 & 0.004 \\
\hline _cons & 0.889 & 0.101 & 8.83 & 0.000 & 0.692 & 1.087 \\
\hline Obs & \multicolumn{6}{|c|}{1429} \\
\hline$R^{2}$ & \multicolumn{6}{|c|}{0.1020} \\
\hline
\end{tabular}

It can be seen that the coefficient of SHARE in Table 5 is -0.373 , and it is significant at a significance level of $10 \%$. Therefore, it can be considered that there is a significant negative relationship between ownership concentration and private information content. That is to say, the higher the ownership concentration, the less private information content may be, and the phenomenon of private information arbitrage will be less, that is, the hypothesis 2 proposed above holds, and the supervisory hypothesis is more applicable in China's financial market. The current level of supervision in China is relatively good; the coefficient of NPMS is -0.013 , and it is significant at the level of $1 \%$, indicating that although the profitability of an enterprise does not have a large impact on the content of private information, the stronger the profitability, it may be to a certain extent, the content of private information is weakened, whose possible reason is that when the enterprise aims to maximize shareholder returns, the enterprise's supervision is stronger, resulting in less private information content; the coefficient of TAT is -0.073 , and it is significant at the level of $10 \%$, indicating that the higher the financial leverage of an enterprise, the less private information content may be, whose possible reason is that the high-indebted enterprise has greater operating risks, so the supervision is stronger, thereby inhibiting the phenomenon of private information arbitrage occur.

\section{Conclusion and Suggestion}

\subsection{Conclusion}

In this paper, the multicollinearity is excluded by calculating the VIF of the variables, and then the BP test is used to find that there is heteroscedasticity. Finally, this paper uses WLS regression to modify the model. The results show that the higher the ownership concentration, the lower the private information content of the enterprise, which means that the hypothesis 2 proposed above holds, and the supervision hypothesis is more applicable in China. Meanwhile, the ownership structure of China's A-share listed enterprises is quite different, so the private information content is quite different, and some enterprises have great investment risks. Moreover, most of the listed enterprises in China have a high ownership concentration, which will reduce private information arbitrage to some extent.

This paper analyzes the impact of ownership structure on private information by studying the relationship between ownership concentration and private information content, verifying the applicability of supervision hypothesis in China 's A-share market. At the same time, the research method in this paper is also universal and can be further extended to other stock markets at home and abroad.

However, due to the differences in ownership concentration, private information content and the influence 
mechanism between the two in different stock markets, studies on other stock markets may obtain different results from this paper. Therefore, the results and conclusions of this study are not necessarily universal, but for the development of China 's A-share market has great reference value and guiding significance. In addition, due to the availability of data, the research object of this paper is mainly large listed companies, while for non-listed companies, this paper has not done further research.

\subsection{Policy Suggestion}

According to the results and conclusions of this study, we found that some policy measures can promote the healthy development of China 's financial markets.

First, at present, most of the listed enterprises in China have a high ownership concentration which can restrain private information arbitrage to a certain extent, so we should try our best to maintain this ownership concentration. But it is also important to prevent excessively high ownership concentration, which may lead to the failure of supervisory hypothesis, thereby increasing private information arbitrage and damaging investors ' interests.

In addition, some enterprises in China have excessively high ownership concentration leading to great risk, and some unprofessional investors may invest in such companies and cause greater losses. Therefore, in order to protect the interests of investors, it is necessary to strengthen the supervision of the ownership structure and maintain good operation of financial markets.

\section{References}

Feng, Y. F., Dong, Y., \& Yuan, Z. B. (2009). Analysis of private information arbitrage in China's stock market based on R 2. Economic Research, 44(8), 50-59, 98. https://doi.org/CNKI:SUN:JJYJ.0.2009-08-004

Kong, X. F., Zhao, Y. J., \& Ma, Y. (2015). Information Environment and Private Information Arbitrage. Modern Business, 391(18), 181-183. https://doi.org/10.14097/j.cnki.5392/2015.18.096

Liu, J. (2019). Private Information and Public Information: An Empirical Study on the Speed of Information Integration in China's Stock Market. Southwestern University of Finance and Economics. Retrieved from https://kns.cnki.net/KCMS/detail/detail.aspx?dbname=CMFD202002\&filename $=1019686880 . \mathrm{nh}$

Malkiel, B. G., \& Fama, E. F. (1970). Efficient capital markets: a review of theory and empirical work. The Journal of Finance, 25, 383-417. https://doi.org/10.1111/j.1540-6261.1970.tb00518.x

Qi, S. C. (2012). Research on the Influencing Factors of the Information Content of China's Shanghai Stock Market. Chongqing University. Retrieved from https://kns.cnki.net/KCMS/detail/detail.aspx?dbname=CMFD201301\&filename=1012050169.nh

Roll, R. (1988). R2. Journal of Finance, 43, 541-66. https://doi.org/10.1111/j.1540-6261.1988.tb04591.x

Wang, C. F., Zhang, S. Q., \& Fang, Z. M. (2018). Research on the Impact of Public Information and Private Information in China's Stock Market on Liquidity. Journal of Tianjin University (Social Science Edition), 20(5), 385-392. https://doi.org/CNKI:SUN:TDXS.0.2018-05-001

Wang, X. H., \& Zhang, Z. J. (2019). Analysis of the characteristics of the equity structure of listed companies in my country. Business Accounting, 654(6), 29-32. https://doi.org/CNKI:SUN:SYKI.0.2019-06-009

Wang, Y. (2006). The complementary effect of public information and private information in China's stock market. Financial Research, 6, 41-52. https://doi.org/CNKI:SUN:JRYJ.0.2006-06-005

Xu, F., Fan, D. Q., \& Xie, D. (2012). An Empirical Study on the Influence of Private Information on Price Volatility in my country's Stock Market. Investment Research, 31(8), 111-120. https://doi.org/CNKI:SUN:TZYJ.0.2012-08-012

\section{Copyrights}

Copyright for this article is retained by the author(s), with first publication rights granted to the journal.

This is an open-access article distributed under the terms and conditions of the Creative Commons Attribution license (http://creativecommons.org/licenses/by/4.0/). 